\begin{tabular}{|c|c|c|c|c|c|c|c|c|c|c|}
\hline $\begin{array}{l}\text { Patient } \\
\text { No }\end{array}$ & $\begin{array}{l}\text { Dyna } \\
\text { CT } \\
\text { used? }\end{array}$ & $\begin{array}{l}\text { \#Coils } \\
\text { used }\end{array}$ & $\begin{array}{l}\text { Total } \\
\text { Coil } \\
\text { Length }\end{array}$ & $\begin{array}{l}\text { Total } \\
\text { procedural } \\
\text { time }\end{array}$ & $\begin{array}{l}\text { Immediate Post- } \\
\text { procedure Angiographic } \\
\text { result }\end{array}$ & Complications & $\begin{array}{l}\text { Follow-up } \\
\text { imaging time } \\
\text { (Months) }\end{array}$ & $\begin{array}{l}\text { Follow-up } \\
\text { imaging } \\
\text { findings }\end{array}$ & $\begin{array}{l}\text { Clinical follow-up } \\
\text { time (Months) }\end{array}$ & $\begin{array}{l}\text { Resolution of } \\
\text { symptoms at follow- } \\
\text { up? }\end{array}$ \\
\hline 1 & $\mathrm{~N}$ & 14 & $198 \mathrm{~cm}$ & $217 \min$ & Complete occlusion & None & 28 & $\begin{array}{l}\text { No residual } \\
\text { fistula (CT) }\end{array}$ & 57 & Yes \\
\hline 2 & $\mathrm{Y}$ & 8 & $98 \mathrm{~cm}$ & $125 \mathrm{~cm}$ & Complete Occlusion & None & 16 & $\begin{array}{l}\text { No residual } \\
\text { fistula (MRA) }\end{array}$ & 21 & Yes \\
\hline 3 & N & 8 & $180 \mathrm{~cm}$ & $287 \mathrm{~cm}$ & Residual Fistula & None & 5 & $\begin{array}{l}\text { No residual } \\
\text { fistula (MRA) }\end{array}$ & 42 & Yes \\
\hline 4 & $\mathrm{~N}$ & 14 & $192 \mathrm{~cm}$ & $337 \mathrm{~cm}$ & Complete Occlusion & $\begin{array}{l}\text { Yes (headache, } \\
\text { nausea, diplopia) }\end{array}$ & 23 & $\begin{array}{l}\text { No residual } \\
\text { fistula } \\
\text { (MRA) }\end{array}$ & 55 & Yes \\
\hline 5 & Y & 6 & $98 \mathrm{~cm}$ & $412 \mathrm{~cm}$ & $\begin{array}{l}\text { Minimal, slow residual } \\
\text { filling }\end{array}$ & None & 7 & $\begin{array}{l}\text { Small residual } \\
\text { fistula }\end{array}$ & 15 & Yes \\
\hline 6 & Y & 12 & $243 \mathrm{~cm}$ & $215 \mathrm{~cm}$ & $\begin{array}{l}\text { Small residual fistula (no } \\
\text { anterior venous drainage) }\end{array}$ & None & 3 & $\begin{array}{l}\text { No residual } \\
\text { fistula }\end{array}$ & 35 & Yes \\
\hline 7 & Y & 19 & $232 \mathrm{~cm}$ & $213 \mathrm{~cm}$ & Complete Occlusion & None & 6 & $\begin{array}{l}\text { No residual } \\
\text { fistula }\end{array}$ & 20 & No (Resolving) \\
\hline 8 & $\mathrm{Y}$ & 7 & $111 \mathrm{~cm}$ & $81 \mathrm{~cm}$ & Complete Occlusion & None & 15 & $\begin{array}{l}\text { No residual } \\
\text { fistula }\end{array}$ & 26 & Yes \\
\hline
\end{tabular}

Methods Patients with endovascular treatment of indirect CCF between 2005-2015 were retrospectively identified and reviewed from our institutional database. The patients were assessed to see if DynaCT was used in the planning of treatment to identify the site of fistula. All patients were divided into two groups- those who had DynaCT used for treatment planning and those who did not. These two groups were further compared in a retrospective cohort study.

Results A total of 8 patients with 9 fistula sites were included, with a mean age of 52.3 years (range 40-67 years). The majority of the fistulas were Barrow Type D (75\%), and $62.5 \%$ of cases also had cortical venous reflux. DynaCT was used in $5 / 8(62.5 \%)$ patients. Transfemoral venous access to the fistula itself was possible in $7 / 8$ patients $(87.5 \%)$. One patient required direct surgical access via ophthalmic vein cut down. 7/8 patients reported resolution of symptoms at clinical follow-up $(87.5 \%)$.

Mean total coil length was significantly shorter for the group who had DynaCT than for the group who did not $(156.4 \mathrm{~cm}$, vs. $190 \mathrm{~cm}, \mathrm{p}=0.035)$. Mean procedural time was 209 minutes for the DynaCT group vs. 280 minutes for the Non-DynaCT group ( $\mathrm{p}=0.12$ ). A transient neurological complication was seen in only one of the patients.

Conclusion The use of DynaCT in pre-procedural planning allows identification of fistula site for indirect CCF and facilitates selective coil embolization of the foot of the vein. This results in the use of significantly shorter total coil length.

Disclosures A. Botsford: None. J. Shiva Shankar: None.

\section{E-093 CONTRAINDICATIONS FOR RADIAL ACCESS IN ENDOVASCULAR THERAPY OF ACUTE ISCHEMIC STROKES}

K Sivakumar, S Feuenwerker, A Tiwari, D Turkel-Parrella, K Arcot, J Farkas. NYU Lutheran Medical Center, Brooklyn, NY

10.1136/neurintsurg-2016-012589.165
Introduction Alternatives to transfemoral access for acute mechanical thrombectomy have been reported and include direct carotid puncture, brachial artery access, and transradial access. This experience is typically based on a rescue scenario where a transfemoral approach is not feasible or has resulted in failure. Large trials have shown the safety of transradial access for coronary intervention with improved morbidity and mortality rates when compared to transfemoral access for cardiology procedures. When considering an alternative access for difficult interventional stroke therapies a primary consideration for using transradial access should be deliberated. This modality has been adapted for ischemic stroke intervention at several centers including our own. However effective, there are instances in which this modality is ineffective or proves difficult to succeed and should be approached with careful consideration.

Methods All patients seeking endovascular therapy secondary to large vessel occlusions and treated by means of radial artery puncture at our center with documented reperfusion outcome were retrospectively reviewed for analysis. In brief, initial consideration for radial approach requires an assessment of coronary vessel tortuosity through CTA. If qualified, a modified Allen's test is thus performed to determine vascularity and eligibility for radial access. Following artery puncture, a microwire is advanced in adjunct to a 6-7 F sheath, typically a Neuron MAX 088. In cases involving severe aortic arch, a CLARET technique is used, employing the aortic arch and valve to form a loop allowing for access into the more distal neuroanatomy. Once the thrombus is visualized, thrombectomy is carried out in the usual fashion. We identify cases wherein transradial access was employed, either as initial or secondary intentions, with unsuccessful clot engagement.

Results A total of 32 patients met criteria in a retrospective review of our database. Reperfusion to mTICI $2 \mathrm{~b} / 3$ was achieved in $78.1 \%(25 / 32)$ of cases. Of the 7 cases unsuccessfully treated through radial access; difficulties in revascularization as specifically relating to this modality were observed in 4 cases. Radial puncture was not attempted in 2 cases due to 
extreme vessel tortuosity. In the remaining 2 cases wherein transradial axis was attempted, thrombus engagement was unsuccessful, either due to physiological morphology or to the upstream distal location of the thrombus.

Conclusion An inherent limitation of transradial access is the restriction to a 6-7 F catheter; however other factors must be considered when identifying cases amenable to radial access.

These factors include extreme tortuosity, which not only presents a challenge for radial access, but for all access modalities, and patient height. Patients of above average height or have distal occlusions present a true challenge to the efficacy of radial access as current catheters are limited in length, and thus unable to reach the desired destination. These contraindications are important factors when considering this method of approach, but technological advances in this field may overcome some or all of these limitations.

Disclosures K. Sivakumar: None. S. Feuerwerker: None. A. Tiwari: None. D. Turkel-Parrella: None. K. Arcot: None. J. Farkas: None.

\section{E-094 THE USE OF ASPIRATION CATHETER SYSTEMS FOR EMBOLIC PROTECTION DURING INTRACRANIAL VERTEBRAL ARTERY ANGIOPLASTY AND STENTING, WITH CONCURRENT USE OF ULTRASOUND TO DOCUMENT FLOW REVERSAL}

S Gesheva, L Hastings, J Wilson. Neurosurgery, LSUHSC New Orleans, New Orleans, LA

\subsection{6/neurintsurg-2016-012589.166}

Background Posterior circulation strokes comprise approximately $20-25 \%$ of all strokes of ischemic origin. Strokes affecting this area carry a significantly higher risk for subsequent stroke or death as compared to anterior circulation strokes. Embolic protection device (EPD) use for carotid artery stenosis has translated into percutaneous interventions of proximal vertebral artery (VA) stenosis. However, the use of EPDs when treating intracranial lesions has yet to be studied and may not be feasible as the vessel caliber is frequently smaller than in existing devices.

Objective The aim of this study is to describe a proximal aspiration technique used during the treatment of intracranial VA and basilar artery (BA) atherosclerotic disease.

Methods Proximal embolic protection was utilized during the treatment of intracranial VA/BA stenosis with angioplasty and stenting in patients with medically refractory disease.

Results Five patients with severe symptomatic posterior circulation stenosis refractory to medical management were treated with angioplasty and stenting utilizing proximal aspiration. Pre- and post-treatment angiograms and MRIs were compared. Treated vascular stenoses were significantly improved, without new neurological deficits or ischemic injury identified on imaging. Ultrasound was utilized to confirm flow reversal during the aspiration portion of the procedure.

Conclusions The proposed technique of proximal embolic protection may help overcome the challenge of embolus propagation inherent to the treatment modality that was encountered during the treatment of intracranial VA/BA stenosis.

Disclosures S. Gesheva: None. L. Hastings: None. J. Wilson: None.

\section{E-095 EARLY HYPERGLYCEMIA PREDICTS POOR OUTCOME DESPITE SUCCESSFUL STROKE THROMBECTOMY}

${ }^{1} \mathrm{~K}$ Dezse, ${ }^{2} \mathrm{~S}$ Bajgur, ${ }^{3} \mathrm{~A}$ Harrison, ${ }^{4} \mathrm{~J}$ Mejilla, ${ }^{4} \mathrm{~W}$ Hicks, ${ }^{3} \mathrm{~T}$ Davis, ${ }^{3} \mathrm{P}$ Pema, ${ }^{3} \mathrm{R}$ Budzik, ${ }^{3} \mathrm{~N}$ Vora. 'Ohio St. University, Columbus, $\mathrm{OH}_{;}{ }^{2}$ Neurosurgery, University of Texas at Houston, Houston, TX; ${ }^{3}$ Neuro-interventional Surgery, Riverside Methodist Hospital, Columbus, $\mathrm{OH}_{;}{ }^{4}$ Neurology, Riverside Methodist Hospital, Columbus, $\mathrm{OH}$

\subsection{6/neurintsurg-2016-012589.167}

Objective Our goal was to identify medical co-morbidities which negatively prognosticate outcome in stroke patients who have successful endovascular reperfusion after imaging-based selection.
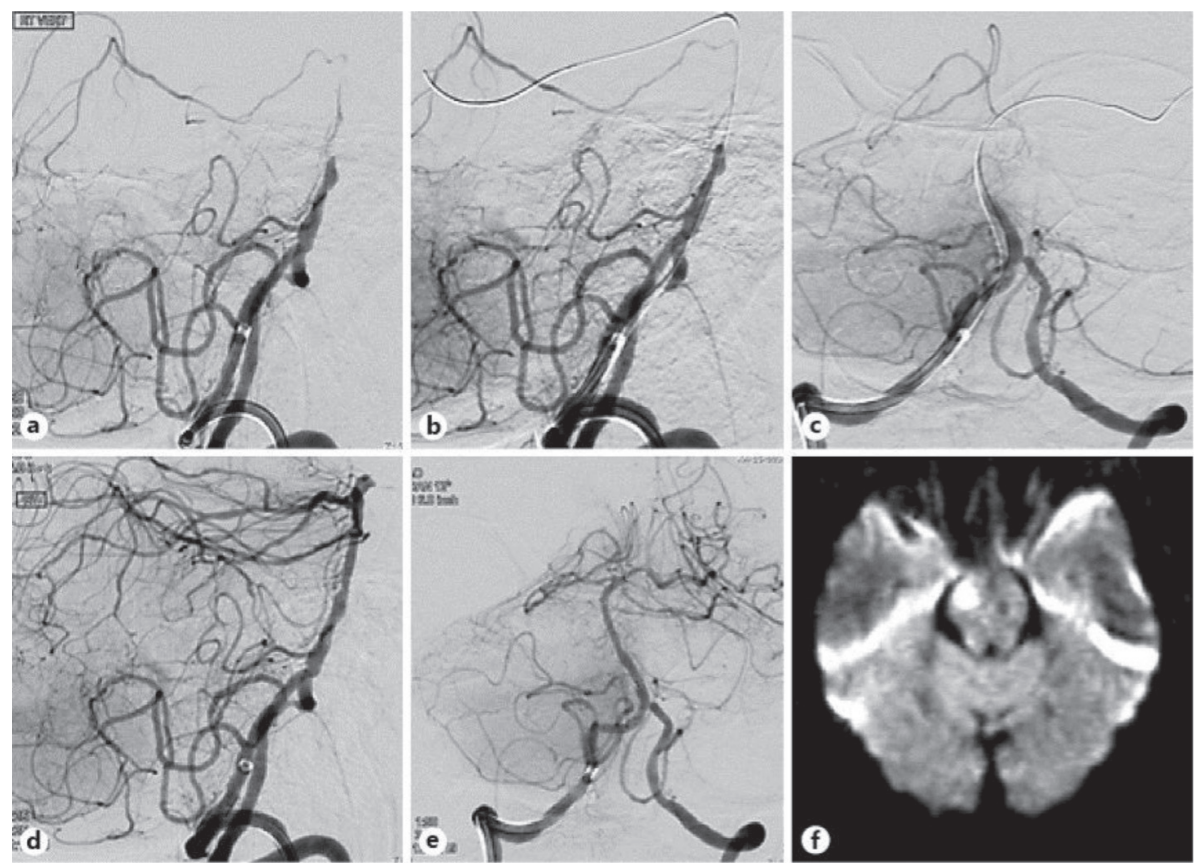